Revista Triângulo

ISSN 2175-1609

\title{
A PRoposta Pedagógica do PRograma bB educar: UMA ANÁlise a PARTIR DO CONCEITO DE CURRÍCULO INTEGRADO
}

\author{
THE PEDAGOGICAL PROPOSAL OF THE BB EDUCAR PROGRAM: AN ANALYSIS FROM THE \\ INTEGRATED CURRICULUM CONCEPT
}
LA PROPUESTA PEDAGÓGICA DEL PROGRAMA BB EDUCAR: UN ANÁLISIS A PARTIR DEL CONCEPTO DE CURRÍCULO INTEGRADO

Maria Clarisse Vieira

E-mail: mclarissev@yahoo.com.br

Luciana de Oliveira Pinto

E-mail: luciana200000@terra.com.br

Universidade de Brasília (UnB)

\begin{abstract}
RESUMO
O objetivo do presente texto é analisar a organização do trabalho pedagógico do Programa BB Educar, da Fundação Banco do Brasil (FBB), voltado para a alfabetização de jovens e adultos, no que tange à sua estrutura curricular. O estudo do material relativo ao Programa e da prática pedagógica vivenciada em diversas turmas do BB Educar é feito com base no modelo de interpretação do currículo de Sacristán (2000). O artigo mostra que o Programa possui uma proposta curricular flexível, que se aproxima do conceito de currículo integrado proposto por Santomé (1998), uma vez que favorece a reflexão crítica acerca dos valores e ideologias que permeiam as questões políticas, econômicas, sociais e culturais que os envolvem.
\end{abstract}

PALAVRAS-CHAVE: Educação de Jovens e Adultos. Programa BB Educar. Currículo integrado.

\section{ABSTRACT}

The purpose of this paper is to analyze the organization of the pedagogical work of the BB Educar Program, of the Banco do Brasil Foundation (FBB), aimed at the literacy of young people and adults, regarding its curricular structure. The study of the material related to the Program and the pedagogical practice lived in different classes of BB Educar is based on the model of interpretation of the curriculum of Sacristan (2000). The article shows that the program has a flexible curricular proposal that approaches the concept of integrated curriculum proposed by Santomé (1998), since it favors the critical reflection on the values and ideologies that permeate political, economic, social and cultural issues that surround them.

KEYWORDS: Youth and Adult Education. BB Educar Program. Integrated curriculum.

\section{RESUMEN}

El objetivo del presente texto es analizar la organización del trabajo pedagógico del Programa BB Educar, de la Fundación Banco do Brasil (FBB), orientado a la alfabetización de jóvenes y adultos, en lo que se refiere a su estructura curricular. El estudio del material relativo al Programa y de la práctica pedagógica vivida en diversas clases del BB Educar se hace con base en el modelo de interpretación del currículo de Sacristán (2000). El artículo muestra que el programa tiene una propuesta curricular flexible, que se aproxima al concepto de currículo integrado propuesto por Santomé (1998), ya que favorece la reflexión crítica acerca de los valores e ideologías que permean las cuestiones políticas, económicas, sociales y culturales que los envuelven.

PALABRAS-CLAVE:: Educación de Jóvenes y Adultos. Programa BB Educar. Currículo integrado. 


\section{INTRODUÇÃO}

A Educação de Jovens e Adultos (EJA) é uma modalidade da educação básica destinada a jovens, adultos e idosos que, ao longo da sua história, não iniciaram ou interromperam sua trajetória escolar. Essas pessoas, sujeitos de saberes constituídos nas experiências vividas, encontram-se à margem do acesso aos bens artísticos, culturais, sociais, econômicos e de direitos, trazendo em si a marca da exclusão.

Tanto a seleção de conteúdos e seus objetivos, quanto a metodologia para o desenvolvimento do currículo da EJA constituem uma posição política, pedagógica e social a ser adotada. Portanto, ao tratar a EJA como uma modalidade voltada para sujeitos da classe trabalhadora é necessário que seu currículo dialogue com as singularidades e incorpore as especificidades e diversidades presentes no universo dos seus sujeitos, considerando, de forma integrada, suas origens, culturas, saberes, conhecimentos e projetos de vida.

Nesse contexto, insere-se o Programa BB Educar, criado em 1994, pelo Banco do Brasil, a partir de parceria com o CEPAFRE (Centro de Educação Paulo Freire de Ceilândia), no Distrito Federal, inicialmente para a alfabetização de seus funcionários e, posteriormente, colocado a serviço da comunidade, em âmbito nacional. Ele visa à alfabetização de jovens e adultos, tendo como base o princípio de que "uma nação só tem um resultado mais efetivo em relação a essa problemática quando a sociedade civil - cidadãos, instituições e empresas participa e exige que o Estado cumpra o seu papel" (FBB, 2004, p. 9).

O presente artigo objetiva analisar a organização pedagógica do Programa no que tange à sua estrutura curricular. O texto está dividido em cinco seções. Na primeira, apresenta-se uma breve retrospectiva histórica da EJA no Brasil e, na sequência, são analisados os fundamentos das principais teorias curriculares vigentes, quais sejam: tradicional, crítica e pós-crítica. Na terceira são discutidas as propostas pedagógicas do BB Educar e, na seção seguinte, a estrutura curricular do Programa, tendo como parâmetro o modelo de interpretação do currículo, de Sacristán (2000), e o conceito de currículo integrado, de Santomé (1998). Por fim, na quinta e última seção, são apresentadas as considerações finais relativas à estrutura curricular investigada.

\section{RETROSPECTIVA HISTÓRICA DA EDUCAÇÃO DE JOVENS E ADULTOS}




\title{
Revista Triângulo
}

ISSN 2175-1609

O Brasil possui, de acordo com a Pesquisa Nacional por Amostra de Domicílios PNAD 2015 (BRASIL, 2016), aproximadamente 12,9 milhões de pessoas maiores de 15 anos analfabetas, o que corresponde a $8 \%$ da população. Esse índice aumenta para 17,1\% ou cerca de 27,6 milhões de pessoas, quando ampliamos o conceito para analfabetismo funcional (pessoas acima de 15 anos e com menos de quatro anos de estudo).

Entretanto, tão preocupante quanto esses indicadores é a constatação de que a EJA possui uma trajetória bastante fragmentada ao longo do tempo e um papel secundário nas políticas públicas voltadas para o setor educacional. Conforme atesta Haddad e Di Pierro (2000), após uma atuação localizada e ineficaz durante todo o período colonial, Império e Primeira República, a Educação de Adultos passa a ser reconhecida como dever do estado e direito do cidadão em 1934, quando a constituição daquele ano, influenciada pelo "Manifesto dos Pioneiros da Educação Nova", de 1932, institui o Plano Nacional de Educação, que prevê o ensino primário integral e gratuito, extensivo aos adultos, como componente da educação pública (BRASIL, 1934).

Somente no final da década de 1940 que a Educação de Adultos veio a se firmar como uma questão de política nacional, com verbas vinculadas e atuação estratégica em todo o território nacional. A extensão das oportunidades educacionais por parte do Estado a um conjunto cada vez maior da população, entretanto:

\begin{abstract}
Servia como mecanismo de acomodação de tensões que cresciam entre as classes sociais nos meios urbanos nacionais. Atendia também ao fim de prover qualificações mínimas à força de trabalho para o bom desempenho dos projetos nacionais de desenvolvimento propostos pelo governo federal. Agora, mais do que as características de desenvolvimento das potencialidades individuais, e, portanto, como ação de promoção individual, a Educação de Adultos passava a ser condição necessária para que o Brasil se realizasse como nação desenvolvida (HADDAD e DI PIERRO, 2000, p. 111).
\end{abstract}

Dentre as várias ações e programas governamentais, nos anos 1940 e 50, destacam-se: a criação da Campanha e do Serviço de Educação de Adultos, ambos em 1947; a Campanha de Educação Rural, iniciada em 1952; e a Campanha Nacional de Erradicação do Analfabetismo, de 1958. Estas campanhas, segundo Vieira (2016), estimularam a reflexão em relação ao analfabetismo e suas consequências psicossociais. Entretanto, não chegaram a criar nenhuma proposta pedagógica especificamente voltada para esse público. Isso só viria a ocorrer no início da década de 1960, com o surgimento de diversas experiências ligadas à 
Educação de Adultos e à cultura popular, organizadas por diferentes instituições da sociedade civil, que passam a implantar projetos, muitos deles com o apoio de governos estaduais e municipais, com um viés mais crítico e reflexivo, voltados para a transformação social e não apenas a incorporação de trabalhadores ao mercado de trabalho.

Dentre eles, é importante ressaltar os Centros Populares de Cultura, da União Nacional dos Estudantes (UNE); a Campanha de Educação Popular, da Paraíba; a Campanha de Pé no Chão Também se Aprende a Ler, de Natal; e, sobretudo, o Movimento de Cultura Popular, de Recife, coordenado por Paulo Freire, que se torna um marco a partir do projeto de alfabetização realizado em Angicos (RN). O que tornava essas propostas distintas daquelas implantadas na década anterior era o compromisso político explícito, assumido com os grupos oprimidos da sociedade, e sua orientação direcionada à efetiva transformação das estruturas sociais, nos moldes defendidos por Mészáros (2008).

Nesse sentido, Ribeiro (1997, p. 23) ressalta que o analfabetismo deixa de ser visto como causa da pobreza e da marginalização e passa "a ser interpretado como efeito da situação de pobreza gerada por uma estrutura social não igualitária”. Essa estrutura, explica Frigotto (2012), é profundamente perversa na medida em que se materializa "dentro da préhistória do gênero humano, como uma sociedade de classes", que mantem:

\begin{abstract}
A divisão dos seres humanos entre aqueles que detêm a propriedade privada de capital (propriedade de meios e instrumentos de produção com o fim de gerar lucro) e aqueles que para se reproduzirem e manter suas vidas e de seus filhos precisam ir ao mercado e vender a sua força de trabalho, tendo em troca remuneração ou salário. (...) Ao capitalista interessa comprar o tempo de trabalho do trabalhador ao menor preço possível, organizá-lo e gerenciá-lo de tal sorte que ao final de um período de trabalho - jornada, semana ou mês - o pagamento em forma de salário represente apenas uma parte de tempo pago e a outra se transforme em ganho do capitalista ou um sobrevalor (mais-valia ou tempo de trabalho não pago) (p. 62-63).
\end{abstract}

A demanda por transformações sociais e a proposta de uma pedagogia emancipadora dos movimentos populares tem boa acolhida pelo governo João Goulart, que promulga, em 1961, a primeira Lei de Diretrizes e Bases da Educação Nacional (LDB) e implanta, em 1963, o Plano Nacional de Alfabetização (PNA), coordenado por Paulo Freire. O PNA, entretanto, é bruscamente interrompido e os seus educadores duramente reprimidos pelo golpe militar de 1964, o que levou ao exílio muitos dos seus líderes, dentre eles o próprio Paulo Freire. 


\section{Revista Triângulo}

ISSN 2175-1609

Em decorrência, a Educação de Adultos passa a ser centralizada no âmbito federal em uma estrutura paralela e autônoma em relação ao Ministério da Educação (MEC), restringindo as suas ações à erradicação do analfabetismo, visto pejorativamente como "uma chaga, mancha vergonhosa a desfigurar as faces da sociedade brasileira, que se apresenta, no conceito dos povos, como constituída, em grande parte, por cidadãos incultos e ignorantes" (BRASIL, 1966). Dessa forma, durante o governo militar, com a criação do Movimento Brasileiro de Alfabetização (MOBRAL) e dos cursos supletivos, a Educação de Adultos volta a ter um caráter compensatório, na medida em que retoma o objetivo de uma alfabetização meramente funcional e não mais uma formação plena e emancipatória, voltada para a cidadania e inserida no bojo de uma política de efetiva transformação econômica e social do País. Nesse contexto, a política educacional implantada era claramente tecnicista, com foco na certificação. Conforme atestam Galvão e Di Pierro (2013):

\footnotetext{
Se a prática da alfabetização desenvolvida pelos movimentos de educação e cultura popular estava vinculada à problematização e à conscientização da população sobre a realidade vivida e o educando era considerado participante ativo no processo de transformação dessa mesma realidade, no contexto econômico e político posterior ao golpe militar a Alfabetização de Adultos cumpre as funções de adaptar o migrante rural aos mercados de trabalho e consumo urbanos e preparar a força de trabalho para o modelo de desenvolvimento concentrador de riquezas, ao mesmo tempo em que servia às estratégias de controle social e legitimação políticoideológica do regime autoritário (p. 48-49).
}

Em 1985, com o fim da ditadura e o início da redemocratização do País, Haddad (2009) constata que se definiu uma nova relação entre a sociedade e o poder público, uma vez que entidades da sociedade civil passaram a assessorar o governo, em todas as suas instâncias, bem como a lutar por uma nova configuração para a Educação de Adultos, mais próxima e aderente aos interesses populares, e que abarcasse o enorme contingente de jovens cerceados no seu direito de estudar.

Neste mesmo ano, a partir do Decreto 91.980/85, o MOBRAL é extinto e substituído pela Fundação Nacional para a Educação de Jovens e Adultos (Fundação Educar), vinculada ao MEC e responsável pelas políticas públicas voltadas para o segmento, com o objetivo de "fomentar a execução de programas de alfabetização e educação básica destinados aos que não tiveram acesso à escola ou que dela foram excluídos prematuramente" (BRASIL, 1985, Art. 1). 


\section{Revista Triângulo}

ISSN 2175-1609

Importante ressaltar que o Decreto em referência é um marco, constituindo-se no primeiro documento oficial a se utilizar da denominação Educação de Jovens e Adultos (EJA) para se referir ao ensino voltado àqueles que não tiveram a oportunidade de cursar a educação básica na idade própria. A partir deste momento, tem início um processo de descentralização da atuação da EJA para os estados e municípios, que assumiram sua inserção nas redes públicas de ensino, bem como passaram a apoiar projetos da sociedade civil, mediante convênios mantidos com a Fundação Educar que asseguravam o repasse de recursos.

Em 1988, uma nova Constituição é promulgada, reafirmando em seu artigo 208 a concepção de que a educação é um direito de todos. Todavia, conforme atesta Vieira (2016, p. 219), as disposições legais existentes não garantiram o cumprimento dos direitos assegurados, uma vez que, na prática, a história da EJA após 1988 "foi marcada pela contradição entre a afirmação do direito no plano jurídico e sua negação pelas políticas públicas".

Dessa forma, em março de 1990, no início do governo Collor, a Fundação Educar é extinta. Em nome do enxugamento da máquina administrativa, o governo federal foi se afastando das atividades da EJA e transferindo as responsabilidades para os estados e municípios. No Governo Fernando Henrique Cardoso, de 1995 a 2002, Haddad (2009) destaca que o direito à escolarização de jovens e adultos não recebeu adequada amplitude na LDB de 1996. Além disso, a EJA foi excluída do Fundo de Manutenção e Desenvolvimento do Ensino Fundamental e de Valorização do Magistério (FUNDEF), principal fonte de financiamento da educação no período. Ele observa ainda que com a implantação do Programa Alfabetização Solidária (PAS), a EJA sofre um grande revés, voltando a revestir-se de um caráter assistencialista, na medida em que sai do âmbito do MEC e passa para a Casa Civil da Presidência da República, alocada sob a égide do Programa Comunidade Solidária, coordenado pela primeira dama Ruth Cardoso.

Havia uma clara opção por levar a responsabilidade pela superação do analfabetismo de jovens e adultos para o campo das políticas tradicionais de combate à pobreza, de natureza compensatória, integrantes da rede de proteção social do governo. Em decorrência, a sociedade civil se mobiliza e cria os Fóruns de Educação de Jovens e Adultos. O primeiro surge em 1996, no Rio de Janeiro, e gradativamente expandem-se para os demais estados 


\section{Revista Triângulo}

ISSN 2175-1609

brasileiros. Nos anos seguintes ganham relevância, passando a ser um espaço de articulação e participação do movimento popular. No tocante ao PAS, Machado (2009) atesta que vários aspectos eram questionados pelos Fóruns, tais como: o conceito de alfabetização utilizado; o curto período destinado à alfabetização; a necessidade de um processo de continuidade de escolarização dos alunos; a falta de eficiência dos questionários de coleta de dados; as dificuldades de acesso aos municípios e os conflitos com a gestão local.

Na gestão do presidente Lula (2003 a 2010) o PAS foi substituído pelo Programa Brasil Alfabetizado (PBA), cuja coordenação fica a cargo do MEC, que restabelece uma relação direta com os estados e municípios para a oferta de cursos de alfabetização para jovens e adultos, mantida pelo Governo Dilma ao longo do seu mandato, de 2011 a 2016. Para exercer a função de regulação das políticas, Di Pierro, Vóvio e Andrade (2008) ressaltam que:

\footnotetext{
A partir de 2004, o Ministério da Educação reuniu a gestão dos programas de apoio à alfabetização e ensino fundamental de jovens e adultos em uma nova Secretaria de Educação Continuada, Alfabetização e Diversidade (SECAD) e instituiu uma Comissão Nacional para consulta aos municípios, estados e organizações da sociedade civil. Essas medidas conferiram maior coerência e eficácia às iniciativas do MEC para essa etapa de ensino, mas não foram suficientes para superar as dificuldades de coordenação interministerial dos programas de Educação de Jovens e Adultos, dispersos em distintos órgãos do governo federal (p. 44-45).
}

Em relação à questão da coordenação da Educação de Jovens e Adultos, Haddad (2009) enfatiza que são vários os programas desenvolvidos no âmbito do governo federal que, junto com a diversidade de projetos desenvolvidos por estados, municípios e entidades da sociedade civil, constituem um conjunto amplo, desarticulado e diverso de propostas, de difícil coordenação e com baixo nível de atendimento ante os elevados índices de analfabetismo e a baixa média de escolarização da população brasileira.

Em síntese, a análise acima demonstra que a Educação de Jovens e Adultos é marcada por uma trajetória fragmentada, repleta de contradições e conflitos calcados, principalmente, nas dicotomias: centralização x descentralização das ações no âmbito da esfera pública e resultados quantitativos x qualidade do ensino. Crítico em relação a esse cenário, Arroyo (2011) acredita que uma das marcas da EJA, ao longo do tempo, tem sido: indefinição, campanhas emergenciais e soluções conjunturais, assumindo um caráter muito mais compensatório e supletivo do que formador e emancipador. 
Ele defende a adoção de um novo olhar em relação aos seus educandos: não mais negativo, rotulando-os pejorativamente como marginais e ignorantes que não tiveram acesso, na infância e adolescência, ao ensino fundamental e médio, ou que dele evadiram-se. Mas sim afirmativo, reconhecendo-os como um coletivo social que teve historicamente negado o direito à educação plena e de qualidade. Afinal, eles vêm de múltiplos espaços formadores, fazem parte de movimentos sociais e de redes comunitárias, ou seja, possuem conhecimentos prévios riquíssimos e uma singularidade própria, que precisam ser reconhecidos pelas instituições educadoras. Dessa forma, os conteúdos escolares precisam ser significativos e aderentes à realidade dos alunos.

Tal questão passa, necessariamente, por uma discussão acerca de currículo, pois conforme atesta Silva (2010, p. 14), "a questão central que serve de pano de fundo para qualquer teoria do currículo é a de saber qual conhecimento deve ser ensinado". Na seção seguinte discutiremos as principais teorias curriculares vigentes.

\section{FUNDAMENTOS DAS PRINCIPAIS TEORIAS CURRICULARES}

De acordo com Silva (2010), podemos distinguir três vertentes curriculares: as tradicionais, as críticas e as pós-críticas. As teorias tradicionais, que surgem no início do século XX e têm em Bobbitt, Tyler e Dewey seus maiores expoentes, pensam o currículo a partir de conceitos técnicos, como planejamento, metas, objetivos, ensino e eficiência; categorias psicológicas, como aprendizagem e desenvolvimento; e imagens estáticas, como grade curricular. Além disso, tem como foco central a questão técnica de "como organizar o currículo", adotando uma suposta neutralidade e aceitando passivamente o "status quo".

As teorias críticas, de viés marxista, por seu turno, surgem no bojo dos movimentos sociais e culturais da década de 60 , e deslocam a ênfase dos conceitos puramente técnicos e pedagógicos para os conceitos de ideologia e poder.

Ela é composta por diversas vertentes que questionam o papel desempenhado pelo currículo e sua suposta neutralidade, uma vez que o concebem como espaço de poder, que é centrado no estado e nas classes dominantes. Postulam a existência de uma subjetividade présocial dos sujeitos, que é contaminada e alterada pelas relações de poder. Esses sujeitos, entretanto, podem libertar-se dessa dominação através de uma pedagogia reflexiva, que leve a 
conscientização desse processo de manipulação e, através de uma postura ativa, engajada e mobilizadora das classes sociais oprimidas, viabilizem a sua emancipação. Destacam ainda, conforme Silva (2010), que essa dominação é exercida não só através do currículo oficial, mas também do "currículo oculto", ou seja, das relações sociais no ambiente escolar, que ocorrem fora das salas de aula e que reproduzem, de forma subliminar, a ideologia dominante. $\mathrm{O}$ fato do currículo ser visto de forma mais ampla, como um processo histórico de construção social, leva a que a pergunta central passe de "quais conhecimentos são válidos e devem ser ensinados?" para “quais conhecimentos são considerados válidos?”, ou seja, o que está por detrás da escolha de certos conteúdos em detrimento de outros.

A teoria pós-crítica surge, a partir das décadas de 1970 e 80, partindo dos princípios da fenomenologia, do pós-estruturalismo e dos ideais multiculturais. Assim como as teorias críticas, discordam das teorias tradicionais, mas transcendem a questão das classes sociais e focam sua análise no sujeito. Ela tem como base a noção de poder descentrado, ou seja, acredita que o poder não tem mais como único centro o estado e as relações de classe, estando disseminado por toda a rede social. Reconhece que o conhecimento é parte inerente do poder e questiona outros processos de dominação centrados na raça, etnia, gênero e sexualidade, que são culturais e estão refletidos no currículo.

Dessa forma, deslocam a ênfase do conceito de ideologia para o de discurso, que é socialmente construído. Acreditam que a diferença não é uma característica natural, mas sim discursivamente produzida. Assim, o conhecimento não é concreto, pois depende da significação que, por sua vez, depende das relações de micropoder.

Além disso, conforme Silva (2010), para essa corrente a subjetividade é social, não existindo nenhum processo de libertação que torne possível a emancipação dos sujeitos, livres e autônomos, uma vez que é rejeitada a hipótese de uma consciência coerente, centrada e unitária. A ciência e o conhecimento não são externos ao poder, mas sim campos de luta em torno da verdade que, por sua vez, vai influenciar os conceitos de identidade. A verdade não é absoluta, é uma questão de poder, no seu sentido mais amplo. Na seção seguinte será analisada a proposta pedagógica do BB Educar e, na sequência, a sua estrutura curricular.

\section{4- PROPOSTA PEDAGÓGICA DO PROGRAMA BB EDUCAR}




\title{
Revista Triângulo
}

ISSN 2175-1609

O Programa BB Educar surge, em 1994, no Distrito Federal, e posteriormente é estendido aos demais estados do País, no bojo de uma série de iniciativas capitaneadas pela sociedade civil no período da redemocratização do País, após a ditadura militar. Nesse sentido, Rêses, Vieira e Reis (2012) ressaltam que o Banco do Brasil:

\begin{abstract}
Preocupado com a existência de analfabetos ou semianalfabetos em seu quadro funcional, procurou o Centro de Educação Paulo Freire de Ceilândia - CEPAFRE para firmar parceria, visando à coordenação de turmas de alfabetização de jovens e adultos. Esse trabalho serviu de embrião para o Programa BB Educar (...) e contou com a presença de Paulo Freire no Departamento de Desenvolvimento de Pessoal do Banco do Brasil - Desed, ocasião em que proferiu palestra sobre a relação entre política e educação, em maio de 1994 (p. 543).
\end{abstract}

Em 2000, o programa passa a ser gerenciado pela FBB e, ao longo do tempo, "tem assumido princípios e diretrizes históricas com ênfase na perspectiva da alfabetização como ato político de libertação dos sujeitos e de transformação social” (FBB, 2004, p. 9).

Verifica-se, dessa forma, que o BB Educar enquadra-se nas políticas de responsabilidade social de uma fundação vinculada a uma empresa do setor financeiro e está à margem do sistema regular de ensino, possuindo, portanto, um caráter não oficial e não certificatório, que o Programa reconhece e, por conseguinte, cobra do Estado uma participação mais efetiva na Educação de Jovens e Adultos. Além disso, conforme atesta Tacca, Carvalho e Coelho Filho (2002, p.6-7) iniciativas "como a do BB Educar revelam que o Banco do Brasil, a exemplo de outras empresas e seguindo tendência internacional, opta por ações sociais que ultrapassam o exercício imediato e provisório da filantropia. Para tanto, busca ações de longo prazo".

A linha político-pedagógica do Programa BB Educar (FBB, 2007a) tem como base a concepção de aprendizagem e desenvolvimento, de Vigotski (2009, 2014), e os princípios de uma educação dialógica e libertadora, de Freire (1987, 1996, 2011), assumindo um enfoque histórico, no qual sujeito e conhecimento são instâncias inacabadas, em permanente construção; social, pois aprendizagem e desenvolvimento são mediados pelo outro e pelo social, uma vez que indivíduo e sociedade são instâncias interdependentes, ou seja, uma não existe sem a outra; e cultural, na medida em que ensinar e aprender influenciam e são influenciados por um conjunto de práticas, instituições e ordens simbólicas por meio das quais os homens se relacionam entre si e com a natureza.

Em decorrência, a concepção de ser humano subjacente é de um ser: 


\title{
Revista Triângulo
}

Histórico, crítico, criativo e inacabado, sujeito aprendente-ensinante que constrói as próprias condições de existência e transforma a realidade, ao mesmo tempo em que se transforma, influenciado pelas condições espirituais e materiais do meio em que vive. Faz cultura e se faz por meio das relações sociais, culturais e ambientais (FBB, 2007a, p. 9).

A educação é vista como um processo ativo e dialético de construção do saber, que pressupõe o permanente diálogo entre quem aprende e quem ensina, entre o conhecimento e o contexto, que ocorre no momento em que:

\begin{abstract}
A herança cultural e a renovação cultural se complementam, possibilitando o espaço possível para a transformação social. Trata-se de um processo em que teoria e prática são indissociáveis e ocorrem em um movimento que inter-relaciona açãoreflexão-teorização-ação: partimos das vivências do grupo, problematizamos tais vivências e voltamos à prática para transformá-la (FBB, 2007a, p. 9).
\end{abstract}

Alfabetizar, portanto, não é ensinar o educando a repetir palavras, mas sim a dizer a sua palavra, criadora de cultura, libertadora e organicamente vinculada a sua realidade de vida. Nesse sentido, Freire (2011) salienta que o importante, de fato, na alfabetização de jovens e adultos, é a aprendizagem da leitura e da escrita como um ato político e criador que envolve, necessariamente, a compreensão crítica da realidade, pois:

O conhecimento do conhecimento anterior, a que os alfabetizandos chegam ao analisar a sua prática no contexto social, lhes abre a possibilidade de um novo conhecimento: conhecimento novo, que indo mais além dos limites do anterior, desvela a razão de ser dos fatos, desmistificando assim as falsas interpretações dos mesmos. Agora, nenhuma separação entre pensamento-linguagem e realidade objetiva, daí que a leitura de um texto demande a "leitura" do contexto social a que se refere (p. 39).

O que se impõe não é a transmissão de um conhecimento previamente elaborado, mas sim a compreensão, por parte do educador, da realidade dos educandos, a fim de desafiá-lo permanentemente a uma reflexão crítica sobre a sua atividade prática, substituindo assim a mera opinião sobre os fatos por uma apreensão e explicação cada vez mais rigorosa.

Numa sociedade na qual o trabalhador é obrigado a vender sua força de trabalho em troca de um salário que é muito inferior ao produto da riqueza por ele gerado, Freire (2011) ressalta que a educação visa apenas a sua capacitação para ser cada vez mais eficiente e gerar, por conseguinte, um excedente cada vez maior para a classe detentora do capital. Dessa forma, quanto mais rentavelmente se combinem: 
A força de trabalho, de um lado, e os meios de produção, de outro, na produção de valor de troca, isto é, da mercadoria vendável, melhor. A educação a serviço desta combinação rentável não pode ter, obviamente, como objetivo desvelar o seu caráter alienador. O que ela tem a fazer, por isso mesmo, é ocultá-lo, reduzindo o processo formador à transferência daquele saber como fazer, tomado como neutro (p. 194).

Por isso, uma educação que vise à emancipação humana deve ser desveladora e instigar o educando a questionar a realidade a sua volta e analisar criticamente o contexto no qual a palavra é construída, qual seja, uma sociedade capitalista, historicamente situada, na qual forças sociais antagônicas lutam pela hegemonia dos seus conceitos e valores. $\mathrm{Na}$ disputa pela palavra está embutida a luta de classe pelo poder, pela supremacia da sua fala. Por isso é tão importante para os educandos terem clareza da disputa em questão, quanto desenvolverem a sua capacidade de expressão e lutarem pelo seu direito de falar a sua palavra e de mudar a sua realidade, pois:

\begin{abstract}
Não há palavra verdadeira que não seja práxis. Daí que dizer a palavra verdadeira seja transformar o mundo. (...) Existir humanamente é pronunciar o mundo, é modificá-lo. O mundo pronunciado, por sua vez, se volta problematizado aos sujeitos pronunciantes, a exigir deles novo pronunciar. Não é no silêncio que os homens se fazem, mas na palavra, no trabalho, na ação-reflexão. Mas se dizer a palavra verdadeira, que é trabalho, que é práxis, é transformar o mundo, dizer a palavra não é privilégio de alguns homens, mas direito de todos os homens. Precisamente por isso, ninguém pode dizer a palavra verdadeira sozinho, ou dizê-la para os outros, num ato de prescrição, com o qual rouba a palavra dos demais (FREIRE, 1987, p. 77-78).
\end{abstract}

Os documentos do BB Educar indicam não apenas ensinar a ler e escrever, mas sobretudo estimular nos alunos uma reflexão sobre a realidade na qual estão inseridos, com vistas a sua transformação em prol de melhores condições de vida para toda a comunidade. Essa reflexão deve ocorrer ao longo da vida, não só nos ambientes escolares, mas em todos os espaços de aprendizagem, pois, conforme atesta Mészáros (2008):

A aprendizagem é verdadeiramente a nossa própria vida. E como tanta coisa é decidida dessa forma, para o bem e para o mal, o êxito depende de se tornar consciente esse processo de aprendizagem, no sentido amplo (...) do termo, de forma a maximizar o melhor e minimizar o pior (p. 48).

Uma vez dominada a leitura e a escrita e cultivada uma visão crítica do mundo, os alunos são estimulados a lutarem pelo seu direito de acesso ao conhecimento historicamente 
produzido pela humanidade e a aprofundarem seus estudos na rede regular de ensino, de forma contínua e permanente, do ensino fundamental à educação superior.

Nesse sentido, Vigotski (2009) afirma que o ambiente escolar, ao viabilizar uma discussão mais aprofundada e sistemática acerca da realidade, incorporando conceitos e induzindo um pensamento mais abstrato, que leva a análise e a generalização, constitui-se num espaço privilegiado para que o desenvolvimento emocional e cognitivo ocorra, e para que sejam viabilizadas novas formas de pensamento, de inserção e atuação dos indivíduos em seu ambiente social. Mas para que essa aprendizagem efetivamente provoque mudanças, deve agir na zona de desenvolvimento potencial dos educandos, ou seja, deve envolver conteúdos ainda não conhecidos, mas passíveis de compreensão a partir da ajuda de colegas e professores. Assim, "o único bom ensino é o que se adianta ao desenvolvimento" (VIGOTSKI, 2014, p. 114).

Dessa forma, se o ensino se mantiver restrito aos conteúdos já conhecidos, no chamado nível do desenvolvimento efetivo, não afetará o individuo e, consequentemente, mudanças não serão engendradas. De igual forma, se for de um nível de complexidade tal que não seja passível de compreensão mesmo com o auxílio de terceiros, o desenvolvimento também não estará sendo viabilizado.

\section{5- PROPOSTA CURRICULAR DO BB EDUCAR}

Conforme atestam as diretrizes curriculares (BRASIL, 2001) e operacionais (BRASIL, 2010) da EJA para o primeiro segmento, essa modalidade de ensino caracteriza-se não só pela diversidade do público que atende e dos contextos em que se realiza, como pela variedade dos modelos de organização dos programas. A legislação educacional brasileira é bastante aberta quanto à carga horária, à duração e aos componentes curriculares desses cursos. Aderente a essa flexibilidade, o Programa BB Educar é implantado nas comunidades a partir de convênios entre a Fundação Banco do Brasil (FBB) e instituições de direito privado, sem fins lucrativos, para compra de material escolar para os alunos e equipamentos para as salas de aula, que normalmente funcionam em igrejas, organizações não governamentais (Ongs), sindicatos, espaços comunitários e sedes de movimentos sociais. 
Revista Triângulo

ISSN 2175-1609

Conforme previsto nas normas operacionais do Programa (FBB, 2015), cada convênio possui um coordenador, responsável por até seis núcleos de alfabetização e capacitado a partir de curso ministrado pela Universidade Corporativa Banco do Brasil (UniBB). Cada núcleo de alfabetização, por sua vez, é gerido por dois alfabetizadores, também capacitados pela UniBB, e composto por, no máximo, 20 alfabetizandos. As turmas têm duração de, no mínimo oito e no máximo 12 meses, com carga horária semanal de seis horas/aula, totalizando, no mínimo, 192 horas/aula.

Em termos socioeconômicos, o público alvo do Programa é homogêneo, sendo composto por pessoas de baixa renda, todavia é bastante heterogêneo do ponto de vista sociocultural, pois abrange homens e mulheres com diferentes trajetórias de vida, profissões, valores e religiões. A faixa etária é bastante ampla, contemplando pessoas de 15 até mais de 70 anos de idade.

A heterogeneidade da turma também está presente no nível de escolaridade inicial, uma vez que pode ser formada tanto por alunos que nunca tiveram a oportunidade de frequentar a escola quanto por outros que, não obstante já terem cursado os anos iniciais do ensino fundamental, possuem dificuldade em utilizarem-se socialmente da leitura e da escrita em função de interrupções frequentes nos estudos e do longo período de afastamento da sala de aula. A aprendizagem dos educandos do BB Educar tem como base os princípios da dialogicidade e do respeito aos seus conhecimentos prévios, nos moldes preconizados por Freire (1996), cuja concepção de currículo identifica-se com os pressupostos da teoria crítica, apresentada na seção anterior, e parte dos seguintes questionamentos:

\footnotetext{
Por que não discutir com os alunos a realidade concreta a que se deva associar a disciplina cujo conteúdo se ensina, a realidade agressiva em que a violência é a constante e a convivência das pessoas é muito maior com a morte do que com a vida? Por que não estabelecer uma "intimidade" entre os saberes curriculares fundamentais aos alunos e a experiência social que eles têm como indivíduos? Por que não discutir as implicações políticas de um tal descaso dos dominantes pelas áreas mais pobres da cidade? A ética de classe embutida neste descaso? (FREIRE, 1996, p. 30)
}

Isso posto, e partindo do conceito de currículo de Sacristán (2000), segundo o qual:

O currículo é uma práxis antes que um objeto estático emanado de um modelo coerente de pensar a educação ou as aprendizagens necessárias. (...) É uma prática, expressão, da função socializadora e cultural que determinada instituição tem, que reagrupa em torno dele uma série de subsistemas ou práticas diversas, entre as quais 


\section{Revista Triângulo}

ISSN 2175-1609

se encontra a prática pedagógica. (...) É uma prática na qual se estabelece um diálogo, por assim dizer, entre agentes sociais, elementos técnicos, alunos que reagem frente a ele, professores que o modelam, etc. (p. 15-16),

Verifica-se que o BB Educar possui uma matriz de referência, composta por conteúdos e objetivos didáticos sugeridos para língua portuguesa e matemática (FBB, 2015, anexo 5), a serem desenvolvidos a partir de planos de aula (FBB, 2015, anexo 6), bem como por uma série de atividades pedagógicas interdisciplinares nestas e em outras áreas do saber (FBB, 2007b). Importante ressaltar que a matriz de referência é apenas sugerida, e não imposta, em respeito à história de vida e à singularidade de cada turma. Ela funciona como uma diretriz curricular indicativa e não normativa, norteada pelos seguintes eixos (FBB 2004):

a) Problematização da realidade: Confronto com os problemas concretos da realidade sobre os quais se debruçam os educandos, analisando e buscando soluções. A intenção é possibilitar a emergência da consciência crítica, a partir de uma visão multilateral da realidade;

b) Trabalho educacional cooperativo: Elaboração conjunta de um saber que resulta da síntese entre as teorizações mais recentes e a prática cotidiana dos alfabetizandos;

c) Democratização do saber: Vida e produção de conhecimento se constituem dialeticamente, num processo que se afirma pela ampliação de oportunidades e possibilidades de construção do saber;

d) Sujeito participante: Papel ativo do educando na sua formação.

As aulas são, portanto, interdisciplinares, planejadas a partir das discussões coletivas, que nortearão as prioridades elencadas pela turma. Assim, a matriz de referência se adequa a turma, e não o contrário. Ela é apenas uma sugestão, e não uma "camisa de força".

Tal procedimento concede autonomia aos educadores para planejar as aulas a partir do perfil, expectativas e conhecimentos prévios da turma, contando, para isso, com o auxílio do coordenador do seu núcleo e dos demais alfabetizadores a ele vinculados, que realizam periodicamente uma avaliação conjunta, com a participação dos educandos, do processo de aprendizagem.

Com base no modelo de interpretação do currículo de Sacristán (2000), abaixo apresentado, mais especificamente ao seu currículo prescrito, que serve de ponto de partida 
Revista Triângulo

ISSN 2175-1609

para a elaboração das propostas pedagógicas do Programa, constata-se que a Proposta pedagógica do BB Educar é flexível, principalmente por não estar vinculado ao sistema regular de ensino.

Figura 1 - Modelo de Interpretação do Currículo

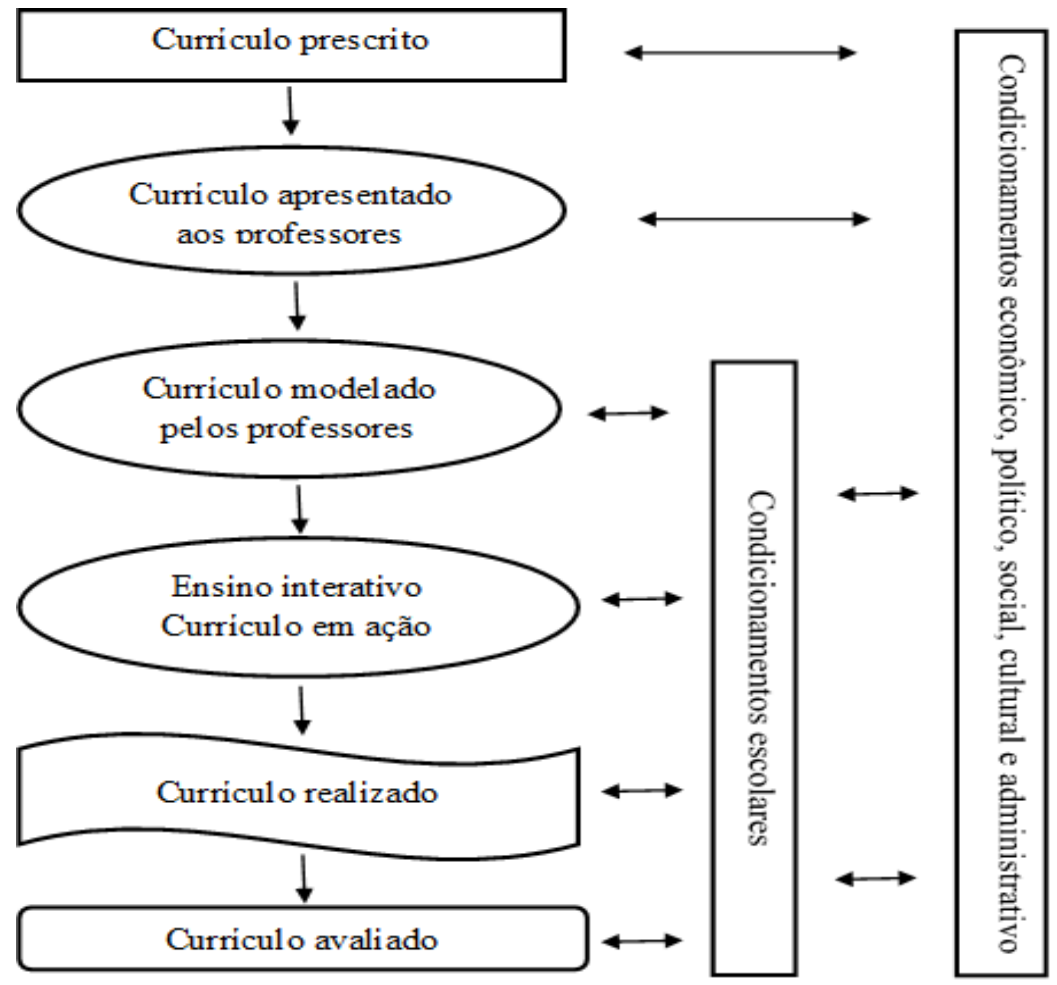

Fonte: Sacristan (2000, p. 105)

A pedagogia freireana, na qual a matriz de referência do Programa se baseia, postula que os temas a serem priorizados em sala de aula devem decorrer dos Círculos de Cultura, prática pedagógica na qual os problemas enfrentados pela comunidade são discutidos por alunos e educadores, sentados em uma grande roda, onde todos se olham e se veem, ensinam e aprendem (FBB, 2004). Ao logo das discussões, que ocorrem cotidianamente, a turma reflete e contextualiza esses temas, substituindo a visão do senso comum por uma visão crítica e social da realidade. Descobrem-se assim novos temas geradores, relacionados com os inicialmente levantados que dão origem, por sua vez, às palavras geradoras, que ao longo do processo de alfabetização são trabalhadas de diversas formas, dando subsídios para a elaboração de textos coletivos, que servirão de "textos base" para o processo de alfabetização, conjugando-se a leitura da palavra escrita à leitura do mundo. 
Revista Triângulo

ISSN 2175-1609

Nestas idas e vindas do concreto para o abstrato e do abstrato para o concreto, volta-se ao concreto problematizado, descobrindo-se os limites e as possibilidades das situações existenciais concretas e evidenciando-se a necessidade de uma ação concreta visando à superação de situações limite.

A partir da análise da estrutura curricular adotada pelo BB Educar, constata-se que ela se aproxima do modelo de currículo integrado proposto por Santomé (1998), na medida em que, dentre outros aspectos, faz com que:

\begin{abstract}
As perguntas ou questões mais vitais e, com frequência conflituosas, que normalmente não podem ser confinadas dentro dos limites de apenas uma disciplina, possam ser formuladas e enfrentadas. (...) [Além disso, contribui] para a criação de hábitos intelectuais que obriguem a levar em consideração as intervenções humanas em todas as perspectivas e pontos de vista possíveis. (...) Também favorece a visibilidade dos valores, ideologias e interesses presentes em todas as questões sociais e culturais. (...) Na medida em que desperta o interesse e a curiosidade dos estudantes, pois o que se estuda sempre está vinculado a questões reais e práticas, estimula os sujeitos a analisar os problemas nos quais se envolvem e a procurar alguma solução para eles. Consequentemente, é um tipo de educação que incentiva a formação de pessoas criativas e inovadoras (p. 122).
\end{abstract}

A integração curricular propicia visões da realidade nas quais as pessoas aparecem como sujeitos da história, como as peças-chave para entender o mundo, ou seja, como uma boa estratégia para estimular o compromisso dos educandos com sua realidade e para obrigarse a uma participação mais ativa, responsável, crítica e eficiente da mesma.

Nesse sentido, saber ler e escrever torna-se instrumento de luta, atividade social e política, aliando-se teoria e prática e tornando o ato de aprender em uma práxis social capaz de transformar a realidade.

\title{
CONSIDERAÇÕES FINAIS
}

Não obstante enquadrar-se nas políticas de responsabilidade social de uma fundação vinculada a uma empresa do setor financeiro e estar à margem do sistema regular de ensino, $\mathrm{o}$ Programa BB Educar cobra do Estado políticas públicas mais efetivas no sentido de viabilizar a esses sujeitos o seu direito de acesso ao conhecimento historicamente produzido pela humanidade, e atua em parceria com os movimentos sociais, organizações não governamentais, sindicatos e igrejas, a partir de uma abordagem histórico-cultural, calcada na 
educação dialógica e libertadora, de Freire (1987, 1996 e 2011), e na concepção de aprendizagem e desenvolvimento, de Vigotski (2009 e 2014).

Com base no modelo de interpretação do currículo de Sacristán (2000), verifica-se que o Programa possui uma proposta curricular flexível. Isso significa que, a partir das aulas ministradas sob a forma de "Círculos de Cultura", são gerados os subsídios indispensáveis para a sua elaboração. Além disso, a referida estrutura se aproxima do conceito de currículo integrado proposto por Santomé (1998), uma vez que favorece a reflexão crítica acerca dos valores e ideologias que permeiam as questões políticas, econômicas, sociais e culturais que os envolvem, bem como desperta o interesse e a curiosidade dos estudantes, na medida em que os assuntos debatidos e estudados estão sempre vinculados à realidade, estimulando a análise dos problemas do cotidiano visando a sua superação.

A análise da proposta curricular do Programa BB Educar mostra que este representa uma contribuição no sentido de proporcionar uma educação crítica, plena e emancipadora para os jovens e adultos que não tiveram a oportunidade, na infância e adolescência, de cursar a educação básica, ou que dela evadiram-se prematuramente por uma série de fatores alheios a sua vontade.

Ele visa contribuir para o resgate de um direito, legalmente previsto na Constituição, e formar cidadãos autônomos e conscientes da sua capacidade criativa e questionadora pois, conforme atesta Marti (apud Mészáros, 2008, p. 58), "ser culto es el único modo de ser libres".

\section{REFERÊNCIAS}

ARROYO, Miguel. Educação de jovens-adultos: um campo de direitos e de responsabilidade pública in: SOARES, Leôncio; GIOVANETTI, Maria Amélia; GOMES, Nilma (Orgs). Diálogos na EJA. Belo Horizonte: Autêntica, 2011.

BRASIL. Constituição da República dos Estados Unidos do Brasil. 1934.

. Ministério da Educação. Alfabetização: Exigência cívica. Brasília, 1966.

Decreto n⿳0 91.980, de 25.11.85. Brasília, 1985.

. Ministério da Educação. Educação para jovens e adultos: ensino fundamental: proposta curricular $\mathbf{- 1}^{\mathbf{0}}$ segmento. Brasília, 2001.

Conselho Nacional de Educação. Resolução CNE/CEB n 3, de 15 de junho de 2010. Institui Diretrizes Operacionais para a EJA. Brasília, 2010.

\begin{tabular}{l|l|l|l|l|l|} 
(C) Rev. Triang. & Uberaba, MG & v.11 & n.2 & p. 211-230 & Maio/Ago. 2018
\end{tabular}


Ministério do Planejamento, Desenvolvimento e Gestão/IBGE. Pesquisa Nacional por Amostra de Domicílios - PNAD 2015. Rio de Janeiro, 2016.

DI PIERRO, Maria Clara; VÓVIO, Claudia; ANDRADE, Eliane. Alfabetização de jovens e adultos no Brasil: lições da prática. Brasília: UNESCO, 2008.

FREIRE, Paulo. Pedagogia do Oprimido. Rio de Janeiro: Paz e Terra, 1987.

Pedagogia da Autonomia: saberes necessários à prática educativa. São Paulo: Paz e Terra, 1996.

Cartas à Guiné-Bissau. São Paulo: Paz e Terra, 2011.

FRIGOTTO, Gaudêncio. Concepções e mudanças no mundo do trabalho e o ensino médio. In: FRIGOTTO, Gaudêncio; CIAVATTA, Maria; RAMOS, Marise (Orgs). Ensino médio integrado: Concepções e contradições. São Paulo (SP): Editora Cortez, 2012.

Fundamentos científicos e técnicos da relação trabalho e educação no Brasil de hoje. In LIMA, Júlio; NEVES, Lúcia (Orgs). Fundamentos da educação escolar do Brasil contemporâneo. Rio de Janeiro: Editora Fiocruz, 2006.

FUNDAÇÃO BANCO DO BRASIL - FBB. Programa BB Educar: Apostila do alfabetizador. Brasília, 2004.

Programa BB Educar. Diário do Alfabetizador. Brasília, 2007a.

Programa BB Educar. Dialogando com o alfabetizador. Brasília, 2007 b.

Programa BB Educar: Bagagem de mão. Brasília, 2015.

GALVÃO, Ana Maria; DI PIERRO, Maria Clara. Preconceito contra o analfabeto. São Paulo: Cortez, 2013.

GDF/SEDF - Governo do Distrito Federal/Secretaria de Estado de Educação. Currículo em Movimento da Educação Básica: Educação de Jovens e Adultos. Vol. 6. Brasília (DF), 2014.

HADDAD, Sérgio. A participação da sociedade civil brasileira na educação de jovens e adultos e na CONFINTEA VI. Revista Brasileira de Educação, v. 14, n. 41, 2009.

HADDAD, Sérgio; DI PIERRO, Maria Clara. Escolarização de jovens e adultos. Revista Brasileira de Educação, n. 14, mai/jun/jul/ago, 2000.

MACHADO, Margarida. A educação de jovens e adultos no Brasil pós-Lei no 9.394/96: a possibilidade de constituir-se como política pública. Revista Em Aberto, v. 22, n. 82, 2009. 
MÉSZÁROS, István. A educação para além do capital. São Paulo: Boitempo, 2008.

RESES, Erlando; VIEIRA, Maria Clarisse; REIS, Renato. Presença e pegadas de Paulo Freire no Distrito Federal. Revista Linhas Críticas, FE/UnB, v. 18, n. 37, p. 529-549, 2012.

RIBEIRO, Vera Masagão. Educação de jovens e adultos: proposta curricular para o $1^{0}$ segmento do ensino fundamental. São Paulo: Ação Educativa, Brasília: MEC, 1997.

SACRISTÁN, José. O currículo: uma reflexão sobre a prática. Porto Alegre: Artmed, 2000.

SANTOMÉ, Jurjo. Globalização e interdisciplinaridade: o currículo integrado. Porto Alegre: Artes Médicas, 1998.

SILVA, Tomaz. Documentos de identidade: Uma introdução às teorias do currículo. Belo Horizonte: Autêntica, 2010.

TACCA, Maria Carmem; CARVALHO, Olgamir; COELHO FILHO, Paulo. Projeto de avaliação externa do Programa de Alfabetização de Jovens e Adultos - BB Educar. $1^{a}$ Etapa (Análise Geral do Programa) Volume I (Diagnostico do Programa BB Educar). Fundação Universitária de Brasília e Fundação Banco do Brasil. Brasília, 2002.

VIEIRA, Maria Clarisse. Memórias-testemunhos de educadores: Contribuições da Educação Popular a Educação de Jovens e Adultos. Curitiba: CRV, 2016.

VIGOTSKI, Lev. A construção do pensamento e da linguagem. São Paulo: Martins Fontes, 2009.

Aprendizagem e desenvolvimento intelectual na idade escolar. In: VIGOTSKI, Lev; LURIA, Alexander; LEONTIEV, Alexis. Linguagem, desenvolvimento e aprendizagem. São Paulo: Ícone, 2014. 